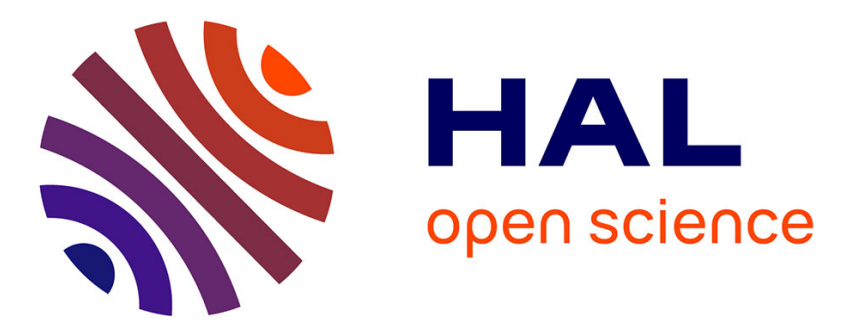

\title{
Finite Element Modeling of Tube Piercing and Creation of a Crack
}

Yvan Chastel, Aliou Diop, Silvio Fanini, Pierre-Olivier Bouchard, Katia

Mocellin

\section{- To cite this version:}

Yvan Chastel, Aliou Diop, Silvio Fanini, Pierre-Olivier Bouchard, Katia Mocellin. Finite Element Modeling of Tube Piercing and Creation of a Crack. 11th ESAFORM Conference on Material Forming, Apr 2008, Lyon, France. pp.Pages 355-358, 10.1007/s12289-008-0068-2 . hal-00510317

\section{HAL Id: hal-00510317 \\ https://hal-mines-paristech.archives-ouvertes.fr/hal-00510317}

Submitted on 18 Aug 2010

HAL is a multi-disciplinary open access archive for the deposit and dissemination of scientific research documents, whether they are published or not. The documents may come from teaching and research institutions in France or abroad, or from public or private research centers.
L'archive ouverte pluridisciplinaire HAL, est destinée au dépôt et à la diffusion de documents scientifiques de niveau recherche, publiés ou non, émanant des établissements d'enseignement et de recherche français ou étrangers, des laboratoires publics ou privés. 


\title{
Finite Element Modeling of Tube Piercing and Creation of a Crack
}

\author{
${\text { Yvan } \text { Chastel }^{1} \text {, Aliou Diop }}^{1}$, Silvio Fanini ${ }^{2}$, P.O. Bouchard ${ }^{1}$, Katia Mocellin ${ }^{1}$ \\ ${ }^{1}$ Centre de Mise en Forme des Matériaux, CEMEF (ENSMP) - rue Claude Daunesse, 06904 Sophia- \\ Antipolis, France \\ URL: http://www-cemef.cma.fr \\ e-mail:yvan.chastel@ensmp.fr
}

${ }^{2}$ DIMEG, University of Padova, Via Venezia 1 - 35131 Padova, Italy

ABSTRACT: A 3D simulation of Mannesmann tube piercing is performed using the finite element software Forge $2005 \AA$. The sensitivity of the simulation results to numerical methods and physical parameters is discussed. Advanced numerical schemes and refined time discretizations are required to obtain correct descriptions of the material flow. In this study, one concentrates on the stress state and damage development before the material comes in contact with the plug. Indeed, the crack is to appear prior to the action of the plug. The description of the material behaviour is found to be a key information to predict the crack development. Predictions based on a modified Lemaitre damage law and a normalised Latham and Cockroft criterion are compared.

Key words: Tube piercing, Mannesmann effect, damage

\section{INTRODUCTION}

The Mannesmann tube piercing is a hot temperature process in which a solid bar is deformed in between two rotating bi-conical rolls. The process relies on the cyclic mechanical loading of the material caused by the conical shape of the rolls and their rotation. The material is pulled-in along a helical trajectory and a depressive mode causes a hole to form and develop in the billet (Figure 3).

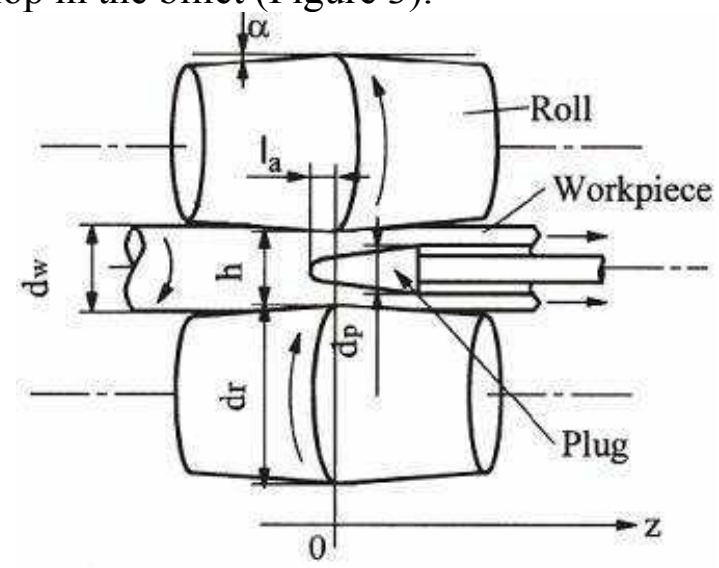

Fig. 1: Schematics of the process and of the tools [1]

The crack starts along the central axis, then expands and propagates. A plug is placed downstream to guide the material outward that a seamless tube can be produced.

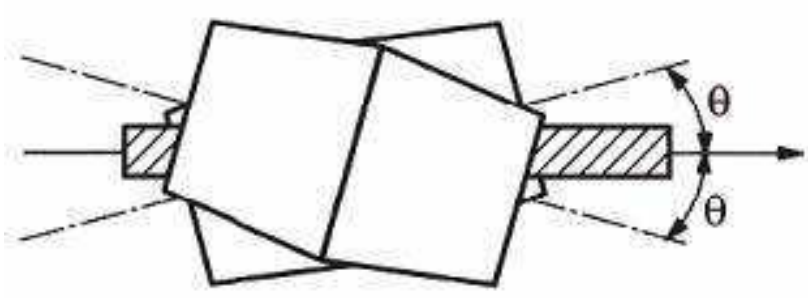

Fig. 2: Orientation of the rolls with respect to the billet [1]

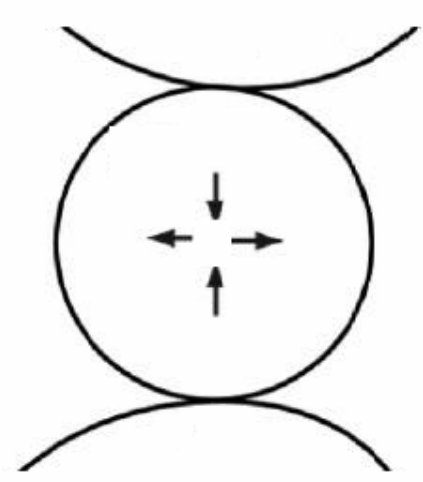

Fig. 3: Stress state in the center of the billet 
The numerical simulation of this process is complex because of the kinematics of the rolls which forces the billet to rotate. A numerical model of the process is presented in this paper. The induced strains are very large. Shear, tensile and compressive modes are combined. One central phenomenon in the process is damage. Rheological models with damage have to be included to track the crack growth and to study the radial expansion which leads to the shaping of the tube. An optimal position is looked for which should take into account the oxidation of the billet material and the progressive wear of the plug (Figure 4). These features are not explicitly included in this paper.

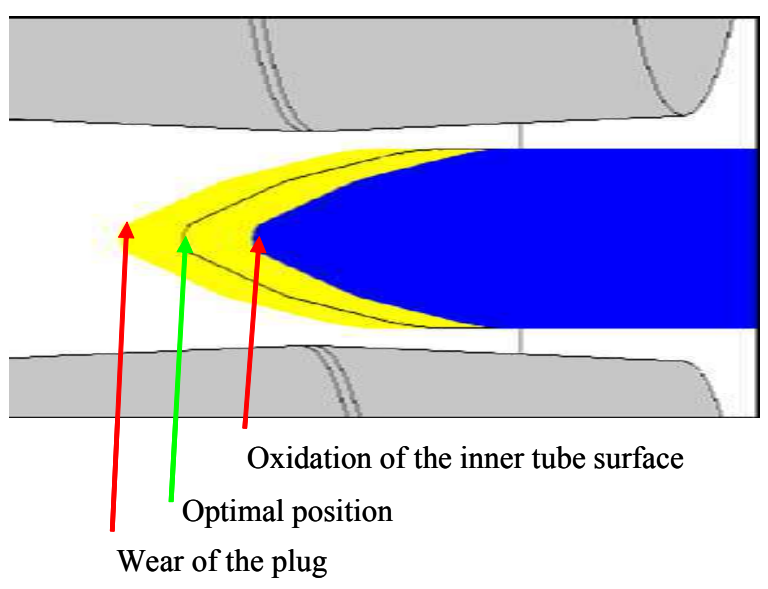

Fig. 4: Positions of the billet and of the plug

\section{THE NUMERICAL MODEL}

The software FORGE2005® is used as the basis for modelling the process. Six tools are included in the model: a pusher, two rolls, two guides and a plug, as depicted in Figure 5. The two rolls are rotating at 70 rotations/minute, and their axes form a $6^{\circ}$ angle. The diameter of the billet is $200 \mathrm{~mm}$ and it is assumed to be at $1250^{\circ} \mathrm{C}$ as it enters the roll bite. At the beginning of the deformation, the temperature of the rolls is taken as $200{ }^{\circ} \mathrm{C}$ and the plug is $800^{\circ} \mathrm{C}$. The constitutive law for the steel grade of interest writes:

$$
\sigma=A \exp \left(T m_{1}\right) \varepsilon^{m_{2}} \dot{\boldsymbol{\varepsilon}}^{m_{3}}
$$

The material parameters are obtained from experimental tests:

$$
\begin{aligned}
& \mathrm{A}=10642 \mathrm{MPa} . \mathrm{s} 3 \\
& \mathrm{~m} 1=-0.004 /{ }^{\circ} \mathrm{C} \\
& \mathrm{m} 2=0.164 \\
& \mathrm{~m} 3=0.119
\end{aligned}
$$

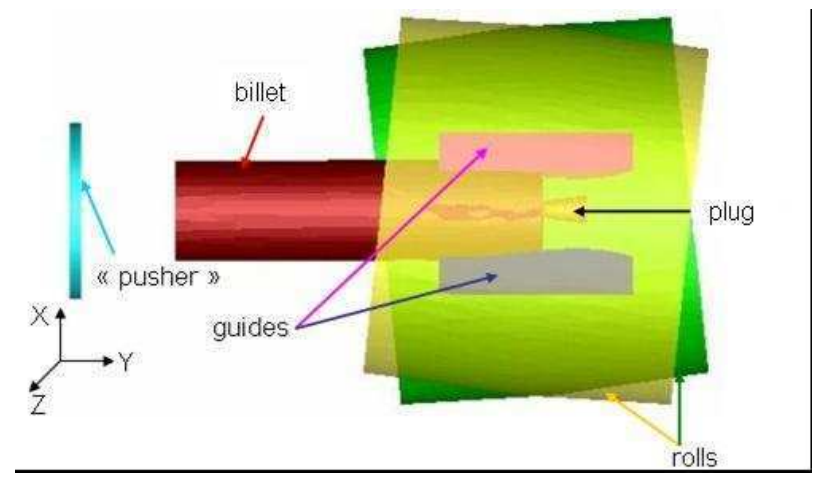

Fig. 5: Position of the tools in the numerical model

The contact with the billet and the rolls is assumed to be close to sticking friction. Sliding modes are applied to model the contacts between the billet and the guides.

\section{NUMERICAL SENSITIVITY ANALYSES}

\subsection{Time discretization}

The billet rotates all along the deformation stage. In updated Lagrangian formulations, large rotations are known to cause numerical volume increase which is artificial and leads to significant errors. The classical update, the explicit Euler scheme, can be written writes as in (2) for an update of the material position $\mathrm{X}$ moving at a velocity $\mathrm{V}$ over a time step $\mathrm{dt}$ :

$$
X_{t+d t}=X_{t}+V_{t} \times d t
$$

For such processes, the second order Runge Kutta scheme as expressed with equations (3) and (4) proves better (see sketch in Figure 6) :

$$
\begin{aligned}
& X_{t+\frac{d t}{2}}=X_{t}+V_{t} \times \frac{d t}{2} \\
& X_{t+d t}=X_{t+\frac{d t}{2}}+V_{t+\frac{d t}{2}} \times \frac{d t}{2}
\end{aligned}
$$

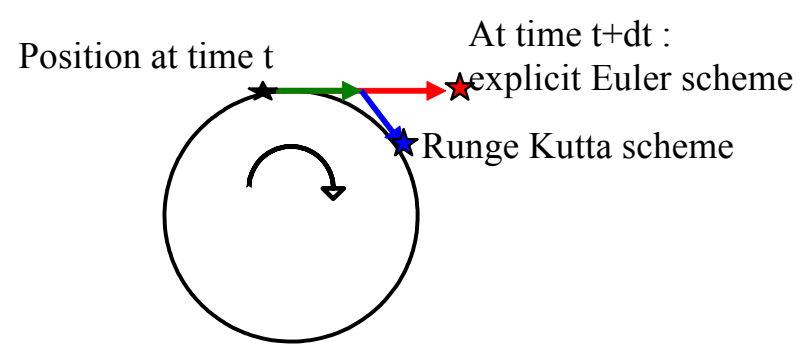

Fig. 6: Numerical update of the configuration over a time step 
In the real tube piercing process, the total deformation time for each material volume is about 5 seconds. Even with a second order Runge Kutta integration scheme, some numerical volume increase is observed. Figure 7 shows a sensitivity study of this volume increase with the time step.

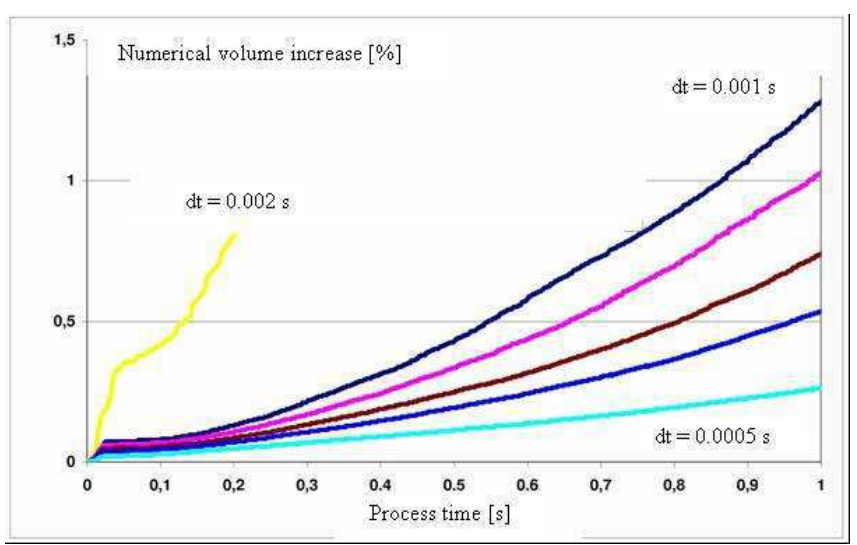

Fig. 7: Volume increase in the numerical simulation during the first second of the process for various time steps

An artificial and excessive shearing at the contact zone with the guiding tools can also be obtained in the numerical simulation at the outer surface of the billet (Figure 8).

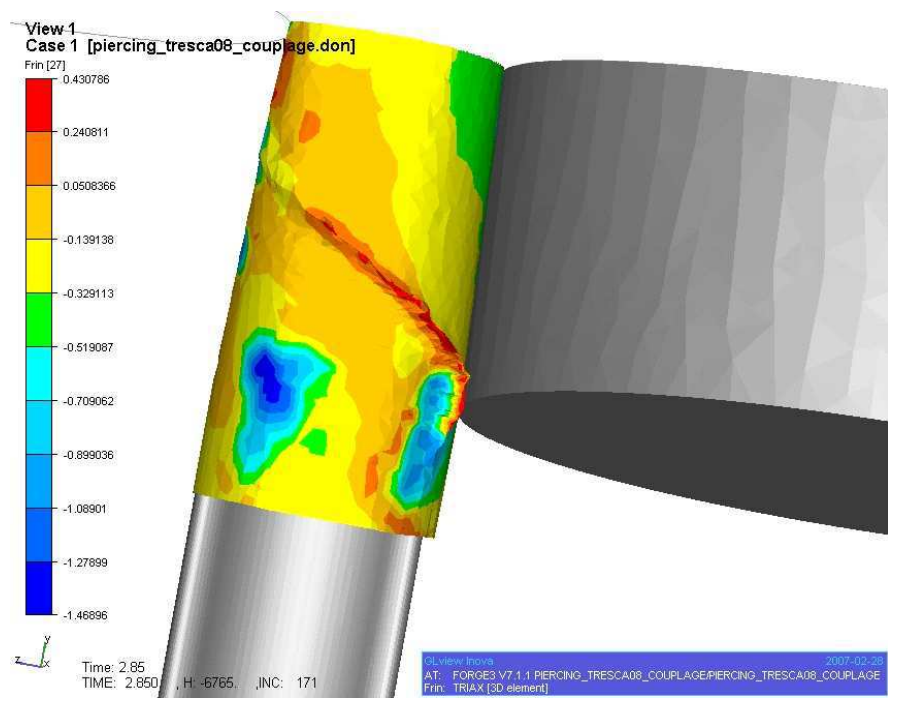

Fig. 8: Stress state in the center of the billet

A small time step can prevent these errors. But, reducing the time step leads to an increase in the required CPU time (Figure 9).

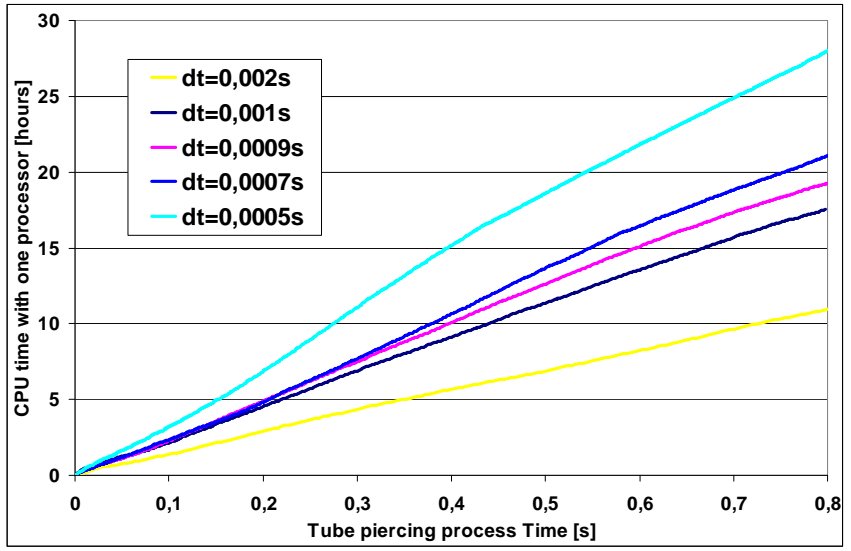

Fig. 9: CPU time required with one processor

\subsection{Stability of the process}

Given the kinematics of the rolls, the billet tends to twist. This is observed in practice. It makes the simulation very difficult since the position is then very sensitive to the friction model for instance. We concentrate on a configuration which would give a stable flow i.e. a flow with a fixed longitudinal axis of the billet as it goes into the roll bite. To enforce this stable motion of the billet in the numerical model, the shape of the two guiding tools is modified (Figure 10).

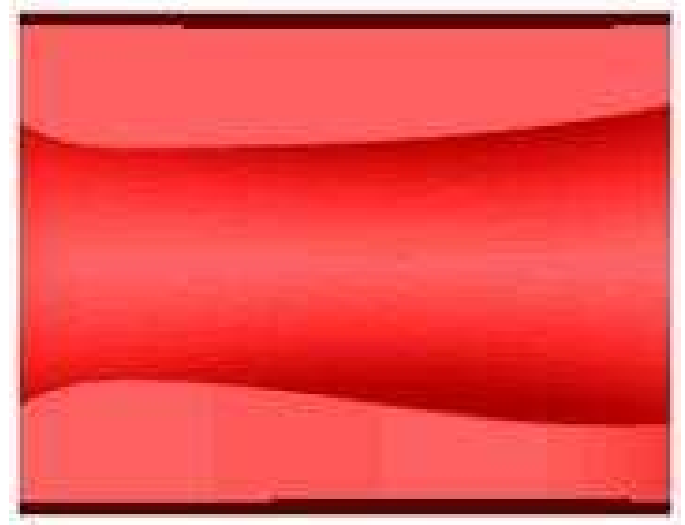

Fig. 10: Guiding tool used in the Finite Element model

\section{MODELLING DAMAGE AND CRACKS}

Two models were used to describe damage evolution during the process, a normalised Latham and Cockcroft and a modified Lemaitre model [2] which is updated incrementally (5): 


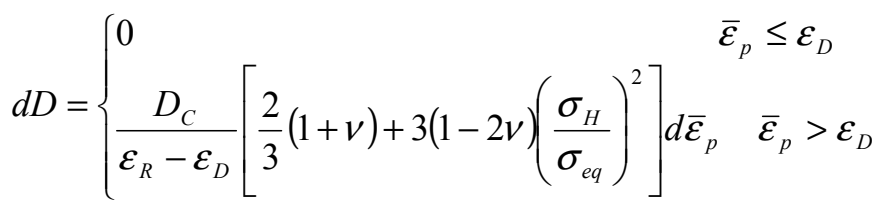

where $\mathrm{D}$ is the damage variable, $\mathrm{E}$ the Young's modulus, $v$ the Poisson's ratio, $\sigma_{H}$ the hydrostatic pressure, $\sigma_{e q}$ the von Mises equivalent stress, $\varepsilon_{D}$ the strain of damage onset, $\varepsilon_{R}$ the strain at fracture, $D_{C}$ the amount of damage at fracture.

This model is modified in order to take into account the loading in tensile on one hand, and in compressive modes on another hand [3]. This is necessary since a material volume of the billet experiences cyclic loading in the tube piercing process. Damage parameters are calibrated using tensile tests and micrographic analysis of the initial porosities in the material. As an example, a map of the damage intensity is shown in Figure 11.

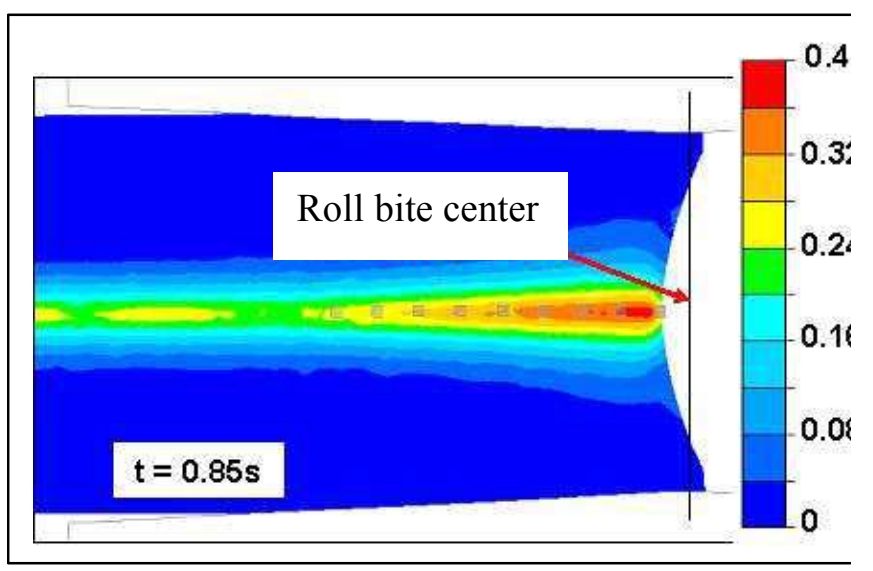

Fig.11: Damage values according to the modified Lemaitre model in a longitudinal cross section of the billet. The line shows the center of the roll bite i.e. the intersection between the central planes of the biconical rolls

The position of maximum damage is predicted along the central axis of the billet, and a critical damage value corresponding to the creation of a crack is found inside the billet, at about $14 \mathrm{~mm}$ within the billet. As observed in the industrial products, the crack is created along the central axis upstream from the roll bite center. A kill element technique is coupled in Forge2005 $\AA$ to show and propagate the crack (Figure 11).

\section{CONCLUSIONS AND PERSPECTIVES}

The tube piercing starting from solid billets has been investigated and modelled using a 3D finite element code. Specific features of the code were used to prevent artificial volume increase and to describe the stable motion of the billet. Rheological and damage models were identified and used to estimate where and when crack is created.

The next step has been to describe the material flow thereafter, once the plug is in place.

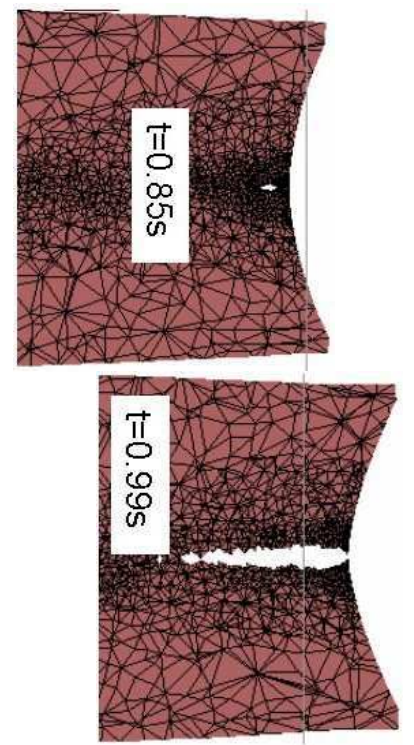

Fig. 12: Crack in the billet after 0.85 and 0.99 second.

\section{REFERENCES}

1. Yang J., Li G., Wu W., Sawamiphakdi K., and Jin D., Process modelling for rotary tube piercing application, Materials Science \& Technology, Vol 2 New Orleans LA (2004) 137-148

2. J. Lemaitre and R. Desmorat, Engineering damage mechanics: ductile, creep, fatigue and brittle failures, Springer-Verlag, Berlin (2005).

3. P.O. Bouchard, L. Bourgeon, Enriched Lemaitre damage approach for cold forging applications, International Symposium on Plasticity, Kona, Hawaii, USA, January 2-8 2008.

4. Fanini S., Ghiotti A., Bruschi S., Evaluation of Fracture Initiation in the Mannesmann Piercing Process, 10th ESAFORM Conference on Material Forming, edited by E. Cueto and F. Chinesta, (2007) American Institute of Physics 978-0-7354-0414-4/07, 709-714.

5. Ceretti E., Giardini C., Attanasio A., Brisotto F. and Capoferri G., Rotary tube piercing study by FEM analysis: 3D simulations and experimental results, Tube \& Pipe Technology (March/April, 2004) 155-159. 